\title{
Assessing Instructors' Perceptions, Practices and Challenges Towards HDP in Higher Institutions: DMU Moderating Clusters in Focus
}

\author{
SIMENEH WASSIE WUBANTE MEKONNEN ENDALAMAW ABATYIHUN \\ Debre Markos University, College of Social Sciences and Humanities, P.O.Box, 269, Debre Markos, Ethiopia
}

(September 2019).

\begin{abstract}
Improving the quality of education in this world should undoubtedly be a focus of attention. HDP is one of the most pressing of all the factors that affect quality of education in the Ethiopian educational institutions. This study investigated instructors' perceptions, practices and challenges in Debre Markos University and its clusters. One hundred and twenty nine HDP graduate instructors of the 2010 E.C academic year were participated in the study. Classroom observation, interview, and questionnaire were used to gather information to the study. The results of the study revealed that most instructors did not practice appropriate active learning methods while teaching their lessons in all observed classrooms. Although instructors witnessed the relevance of HDP training in all phases of teaching and learning process, their actual practices showed that the reverse. In addition, lack of interest, the irrelevance content of the training manual with the classroom course and absence of well-organized follow-up support were the major challenges of instructors for implementing HDP while teaching various courses. The study wrapped up with some plausible recommendations that alleviate or minimizes the effect of barriers.
\end{abstract}

Keywords: HDP, Perceptions, Practices, Challenges

DOI: $10.7176 /$ RHSS/9-19-05

Publication date:October $31^{\text {st }} 2019$

\section{INTRODUCTION}

\section{Background of the Study}

Education is one of the key measures to know the consequence of globalization to build the capacity of human capital accumulation- which apparently calls for increased training and re-training to consume the knowledge and skills that are rapidly produced by center of knowledge. As a result of this, higher institutions have been dramatically changing to present themselves as viable centers of lifelong learning of high quality.

As Benson (1963: 33-41) states that attention to the concept of quality education has come to the most noticeable issue as learning, parents and communities, educators, leaders and nations acknowledge that what is learned and how learning occur is an important access to education. But one difficulty is that while most people understand intuitively what they mean by "quality education'.

According to UNESCO (2003:3), the controversial definition of quality education is linked directly to critical components as teachers, contents, methodologies, curriculum, examination, system policy, planning management and administration. Thus quality education requires well- trained teachers who are equipped with good attitude, perceptions and able to challenge the constraints in the overall education system.

Indeed, instructors need to have a rich and flexible understanding of the subject matter in order to teach in ways that are responsive to students thinking and which foster learning with understanding (Anto, 2006 as cited in Yilfashewa, 2011). In addition, content specific professional development enables teachers to feel wellinformed about curricular and instructional alternatives, learning styles, adolescent development, and assessments (Robinson, 2011 as stated in Blackmon, 2013).

The Ethiopian educational system adopted different schemes aimed at transforming its approach to achieve quality education. The Higher Diploma Programme (HDP) is one of those schemes adopted to familiarize teacher trainees with more up-to-date pedagogic methods.

HDP began in all teacher training colleges and universities since October 2002 G.C. as a new compulsory qualification for all teacher educators (MOE, 2011:4). It aimed at improving the quality of classroom practice. It provides teacher educators with practice of programme to support their development as effective teachers and reflective practitioners with enhanced professional status, able to model student centered learning and continuous assessment, manage changes and make a difference in education system(HDP Hand Book 2011:6).

It is also believed that in our education system, the Higher Diploma Program (HDP) would have the potential to equip teacher educators with the necessary pedagogical skills and keep them up-to-date to cope up with the current technology. Various studies in professional development practices signify that university instructors are good in their academic knowledge and qualification and their weakness lie in their inability to employ the teaching approaches, classroom management and students' assessment that are set in policies(HDP 
Handbook, 2011).

The study conducted by Ministry of Education in 2002 covering the overall education system of Ethiopia and teacher's education system revealed that Ethiopian educators failed to form spearhead in educational development endeavor. The teaching learning process they were employing so far was teacher dominated talk and blackboard use. The study also attributed that the major cause of the problem to the fact that teacher educators have received very little or no opportunity to undertake appropriate and necessary staff development that could enable them to perform their key roles in rendering pre-service and in-service education in line with a student centered approach. Consequently, HDP is considered as one of the basic tools by the ministry of education in order to tackle the underlying problems.

The program is a government initiative and the control is highly centralized. Hence, the same practice is taking place in all departments of the universities and in colleges in Ethiopia. In general, classroom teaching methods play a key role in producing competent teachers. Though the training policy of the government is intended to improve the quality teacher educators, it also needs too many programs to realize its intended missions. Among these higher Diploma program is one which plays its own role in classroom teaching.

The government of Ethiopia has given due attention to education as principle development sector, in particular, higher education is considered to ensure the need for trained and skilled manpower.

In the same vein, DMU is committed to a big national mission in relation to producing capable human resources for the economy without which growth and transformation of the nation is impossible. In doing so, the Higher Diploma Programme in Debre Markos University has been implementing since the last nine years, and the university also working as a moderating university with five cluster Teacher Training Colleges, namely: Debre Markos CTE, Finote Selam CTE, Injibara CTE, Gilgelbeles CTE, Fiche CTE, Burie Campus and the HDP in Debre Markos University itself.

As a result, the literature showed those teachers' perceptions, practices and challenges towards HDP in Ethiopia Education system, particularly in our university with cluster colleges mentioned above is not investigated. Therefore, the study attempted to assess the instructors' perceptions, practices and challenges towards HDP.

\section{Statement of the Problem}

HDP serves dual purpose. For one thing, it provides teacher educators with practical implementation of the courses (contents) in using varied active learning methods. For the other, it makes teacher educators reflective in their daily lessons. These objectives will be achieved only if the appropriate teaching methods in the classroom are employed with a reasonable quality as that of a training conducted in the HDP sessions.

HDP is a one year on-job training that provides an opportunity for instructors to try immediately the training skills in their classroom teaching and reflect upon it. Apart from this, instructors plan their lesson based on the training they are receiving, conduct a session, and evaluate the lesson and again plan for improvement. The leaders will evaluate progress of each instructor by referring to the individual teacher educators' portfolios.

Literature on staff development practice indicates that the success of a given professional development training measured by the degree of the transfer of the training skills into classroom instruction (Guskey, 2000). The ideas raised above should become fruitful when the HDP attendants give careful attention to the training.

Ashenafi (2017), Adula (2008), Desalegn(no date), and Zelalem (2017) conducted researches on HDP implementation, Application of HDP, CPD, and Teachers' perceptions towards HDP in different institutions respectively. Their findings showed that higher institution HDP training has a great value for the instructors and in improving their professional development. Those researchers also showed in their findings that the HDP module, its mode of delivery and the program by itself need some amendment.

In line with this, the researchers' experiences told them that even if the program is done in all institutions, there are no changes seen on the trainees after they have accomplished the HDP training and its impacts is not observed in the classroom. There are also doubts about the implementation of HDP in higher institutions truly following the right procedures on the targeted purpose. Moreover, as far as we have taken the HDP training and one of the researchers has been working as HDP leader and tutor, most trainees were reluctant to attend the programme most often. This reveals that there might be problems in relation to their perceptions, and challenges encounter. And those who start to attend the programme might not accomplish all the expected tasks well. These problems might have their own impact on the program in creating trained and skilled manpower in the long run and also adversely affects the quality of the education system. These and other related factors initiate the researchers to conduct the research to know the existing realities in the overall practices of the HDP training and its challenges in our university and with cluster Colleges of Teacher Education.

Thus, the study tries to answer the following research questions:

1. What perceptions do instructors hold in implementing HDP?

2. What are the major practices employed by instructors after completing HDP?

3. What challenges do instructors' face in implementing HDP? 


\section{Objectives of the Study}

General Objective

This study intended to assess the instructors' perceptions, practices and challenges towards HDP in higher institutions.

\section{Specific Objectives}

1. To examine the instructors' perceptions towards HDP training.

2. To determine the major practices employed by instructors in implementing HDP in the classroom.

3. To examine the challenges of instructors in implementing HDP in higher institutions.

\section{Significance of the Study}

The study tries to assess the instructors' perceptions, practices and challenges towards HDP training in higher institutions. Therefore, this will help the concerned body at different levels (HDP attendants in higher institutions, HDP coordinators, Ministry of Education, and other education faculties and departments) to revisit their procedure, which result in effectiveness and sustainability of the program. In addition, the perceptions, practices and challenges of instructors which will be discussed in the study will have the following importance.

1. The study is expected to contribute in the identification of the instructors' perceptions, practices and challenges towards HDP training in higher institutions.

2. It is intended to create awareness to the HDP training attendants in particular and HDP related coordinators at large.

3. The study may help as a springboard for those who want to conduct further investigation on similar area.

\section{Limitation of the Study}

The overall design of this descriptive study included certain limitations. One limitation may have been our knowledge and work with Higher Diploma Program. For the last few years, we have not only been an active member of a Higher Diploma Program training, but also the HDL in two Debre Markos University and Burie Campus. This level of previous involvement and knowledge of HDP could have ultimately skewed the interpretation of the data because of our biases and beliefs. Furthermore, the design of this research limits the overall application of the results to other settings.

However, findings from this study provide an in-depth understanding for university academic management body, HDP Coordinators and Leaders who are seeking to better understand the perceptions of teachers in regards to HDP. The findings provide for them with insight from the teachers' perspectives, which is a powerful tool when trying to gain support during the implementation phase. The information obtained during this study could be used to support the implementation of HDP training for teachers in similar university and other similar settings.

\section{RESEARCH METHODOLOGY \\ Research Design}

This study employed a descriptive survey research design. Survey design was chosen since it was useful to assess the instructors' perceptions, practices and challenges towards HDP in different higher institutions. This method was also selected because of its usefulness in explaining the existing situation or phenomenon based on samples that represent a population (Creswell, 2003).

\section{Research Population}

The target populations of the study were all instructors who completed the HDP in 2010 E.C in DMU, in Debre Markos CTE, in Burie Campus, in Finoteselam CTE, in Injibara CTE, in GilgelBeles CTE and in Fiche CTE. The university, the campus and colleges were selected on the basis of the proximity and accessibility of the target population to the researchers. Moreover, all the colleges listed above are moderated by Debre Markos University. The total population of the study is indicated in the following table. 
Table 1: Demographic Distribution of the Population

\begin{tabular}{|l|l|c|c|c|}
\hline \multirow{2}{*}{ No. } & \multicolumn{1}{|c|}{ Study Area } & \multicolumn{3}{c|}{ Population } \\
\cline { 3 - 5 } & & M & F & T \\
\hline 1 & DMU & 56 & 13 & 69 \\
\hline 2 & Burie Campus & 18 & 3 & 21 \\
\hline 3 & Finote Selam & 15 & - & 15 \\
\hline 4 & DMCTE & - & - & - \\
\hline 5 & Injibara & 15 & - & 15 \\
\hline 6 & Fiche Total & 5 & - & 5 \\
\hline 7 & GilgelBeles & 4 & - & 4 \\
\hline \multicolumn{1}{|c|}{ Tyyy } & $\mathbf{1 1 3}$ & $\mathbf{1 6}$ & $\mathbf{1 2 9}$ \\
\hline
\end{tabular}

As indicated in table 1, the number of HDP graduates from Debre Markos university and its cluster colleges was 129 (males113 and females 16). Unfortunately, Debre Markos College of Teacher Education had no any of HDP graduates in 2010 E.C. Therefore, the researchers excluded it from the present study.

\section{Sampling Techniques}

Four instructors and a leader from each study area were selected for interview (30) through systematic random sampling technique. All the classroom sessions who were interviewed in the study areas were observed accordingly. The designed questionnaires were distributed for all instructors (127) through comprehensive sampling technique.

\section{Data Collection Instruments}

In this study, a variety of instruments were used to collect information about the HDP training attendants' perceptions, practices and challenges.

\section{Classroom Observation}

Classroom observation was conducted in order to collect first-hand information regarding the current instructors' perceptions, practices and challenges towards implementing HDP in higher institutions. Accordingly, all HDP trained instructors' sessions from university, campus and colleges were observed (30) by means of an observation checklist. The observation checklist was adapted from HDP Handbook Guidance (MOE, 2011). An expert appraisal was used to ensure whether the adapted checklists could fit to the HDP training or not. Generally, the observation checklists focused on HDP trained instructors' perceptions, practices and challenges towards the program.

\section{Interview}

Interview was another important instrument used in this study. It helped the researchers to collect information from different sources. In the first instance, interview wasused to collect information from candidates in order to assess their perceptions towards HDP training. Therefore, the researchers selected thirty instructors including a leader for interview purposely from each study area in order to assess the instructors' perceptions, practices and challenges towards HDP. The guided interview questions were adapted from Higher Diploma Program Hand Book Guidance (2011).

\section{Questionnaire}

The aim of the questionnaire was to obtain data that will help to answer the research questions and to achieve the objectives of the study. It was prepared by the researchers through consultation with related literatures and the HDP guidance (2011). HDP candidate's questionnaire had three major components. These were instructors' perceptions, practices and challenges towards HDP training in higher institutions. All participants in the selected study areas were asked (129) to fill in the questionnaires.

\section{Data Collection Procedures}

In this study, three types of data collection methods were employed to examine instructors' perceptions, practices and challenges towards HDP in Higher Institutions. For the purpose of this study, first, the researchers met the deans and discussed the purpose of the research activity showing the support letter, which was later distributed to all departments through office vice dean. Then, the researchers approached to include instructors, a leader or a tutor from each department of the university and colleges.

The selection took place in such a way that the researchers visited the department at any of appropriate time and asked the target instructor, clarifying the objective of the research, if he/she was willing to be observed during his/her classroom instruction and then interviewed. 
The classroom observation was held with the help of observation checklist in order to observe the natural circumstances. The observation focused on areas of instructors 'perceptions, skills and practices including their challenges that were applied at a classroom level. Data collection during classroom observation took place in such a way that the researchers took notes thereby tick as yes or no. (See appendix 1).

Then, interview held with the respective instructor, and then the respective individuals investigate further about instructors' perceptions, practices and other challenges they thought towards implementing HDP for promoting professional development. Interview contained the semi-structured interview guide that let the interviewee to express his/her feeling purposely. The number of questions and scope of each interview guide questions for this study set were taken into consideration on the basis of the availability of the time for both the interviewer and the interviewee. (See the interview questions in appendix 2).

Finally, the devices of data collection for this study were encompassed one-page separate written research questionnaire for instructors. The researchers contacted all instructors in university, campus and colleges. Then, the printed copy of questionnaires were composed and distributed to the participants between November and December of 2018. The pedagogical goal of the survey was to explain and ask the participants to answer the questions. They then filled in the questionnaires quite willingly. The questionnaires for this survey looked for instructors' perceptions, practices, and challenges towards implementing HDP in higher institutions. (See appendix 3). Then, the obtained data from all instruments was coded by the researchers and analyzed qualitatively and quantitatively.

\section{Data Analysis Techniques}

This research used both qualitative and quantitative aspect of data analysis. The data which was collected with the help of interview from each interviewee was transcribed and coded with reference to the research questions. The data obtained from classroom checklist was quantitatively analyzed. After the questionnaires were returned from respondents (129), data was gathered from respondents. Then, the results were tabulated in such a way that it described the results of responses to the given item. The data which was collected from different sources was analyzed independently following the research questions. Finally, the result of the data from all sources and instruments was discussed all together. Then, conclusion and recommendation were forwarded.

\section{CHAPTER FOUR: RESULTS AND DISCUSSION}

\section{Results and Discussions}

This study intended to assess the instructors' perceptions, practices and challenges towards HDP in higher institutions. The data was collected through classroom observation, interview and questionnaire. To provide focus for this research, the following questions were developed and explored:

1. What perceptions do instructors hold in implementing HDP?

2. What are the major practices employed by instructors after completing HDP?

3. What challenges do instructors' face in implementing HDP?

\section{Major Practices of Instructors in Actual Classrooms after HDP Training}

This section discusses the results found from different instruments towards instructors' HDP training on various aspects. For this, 30 instructors were observed in the study areas (Debre Markos University, Burie Campus, Finote Selam CTE, Injibara CTE, Gilgel Beles CTE, and Fiche CTE, 5 from each.) This section presents the results obtained from observation on participant instructors.

Table 1: Observation Results of Instructors Major Activities in Actual Classrooms after HDP Training

\begin{tabular}{|c|c|c|c|c|c|}
\hline \multirow[t]{3}{*}{ No. } & \multirow[t]{3}{*}{ Items } & \multicolumn{4}{|c|}{ Responses } \\
\hline & & \multicolumn{2}{|c|}{ Yes } & \multicolumn{2}{|c|}{ No } \\
\hline & & $\mathbf{N}$ & $\%$ & $\mathbf{N}$ & $\%$ \\
\hline 1 & Can the teacher implement various teaching methods? & 6 & 20 & 24 & 80 \\
\hline 2 & Can the teacher become a role model in his/her teaching practices? & 9 & 30 & 21 & 70 \\
\hline 3 & Is the teacher working hard to make him/herself a better reflective teacher? & 12 & 40 & 18 & 60 \\
\hline 4 & Can the teacher manage his/her time properly? & 6 & 20 & 24 & 80 \\
\hline 5 & Can the teacher motivate his/her students? & 9 & 30 & 21 & 70 \\
\hline 6 & Can the teacher assess his/her students' performance through criteria? & 6 & 20 & 24 & 80 \\
\hline 7 & Can the teacher actively participate in working with his/her students? & 6 & 20 & 24 & 80 \\
\hline 8 & Does the teacher have a plan on various academic sessions? & 9 & 30 & 21 & 70 \\
\hline 9 & $\begin{array}{l}\text { Can the teacher apply different active learning methods in his/her actual } \\
\text { classrooms? }\end{array}$ & 12 & 40 & 18 & 60 \\
\hline 10 & Can the teacher manage his/her classroom properly? & 12 & 40 & 18 & 60 \\
\hline
\end{tabular}

According to the results observed from 30 sections in the five higher institutions, all instructors did not 
apply the active teaching methods in their actual classrooms. They almost (above 60\%) focused on lecturing method. They taught all of their lessons on teacher-centered approach. This implies that almost all instructors in the observed areas did not use various active learning methods while teaching various contents of their lessons.

The finding obtained from the table is contrasted with the most common and basic active learning techniques that are suggested in the HDP handbook (MOE, 2011) like Visual Aids, Gapped Lectures, Buzz Group, Questions and Answers, Active Listening, Written Material, Research, Demonstrations ,Interactive Learning, Independent learning, Pair work, Pyramiding, Group work, Jigsaw groups, Cross over groups , and Cooperative learning. When students discuss ideas and if they make a diagram of their thoughts, it can help visual learners. The following are different forms of diagrams that students can make in groups, pairs or individually. These include Brainstorming, Spider diagram, Mind map and Thought bubble If a teacher wants his/her students to consider ideas a little more deeply and to clarify their opinions, he/she could use Stimulus material, Picture analysis, Case studies, Ranking tasks, Matching exercises, Flashcards, Debate, Decision Line, Balloon game, and Role play, Hot seating, Drama, Simulation exercises, Storytelling, and Speeches. Giving Tasks and Assignments can also be used as ALMs. To do so, the teacher provides his/her students pieces of work that students can complete individually or in groups. These could include Creative writing, Report writing, Diary, Newspaper or radio reporting, Drawing a picture, map or graph, Assignment or homework, Problem solving and Presentation A central concept of active learning is that students learn best when they learn from experience. Therefore, all instructors in the study areas should see themselves against such teaching and learning techniques.

Moreover, there are methods to make their lectures more interactive (Pollard, 2008). Most importantly, in active learning, teachers should provide their students with opportunities to do some work based on the ideas given for them. Therefore, teachers are expected to use a range of variety of active learning methods to address the different needs of their students and to promote students learning styles.

\section{Instructors' Interview Results}

HDP Graduated instructors (25) were asked various questions towards their HDP training in their work areas. Their responses are discussed in the following section.

The first question to the respondent instructors was HDP Training contributes many purposes in relation to professional development. State the major ones. They replied:

Many of the Higher Diploma Candidates in this study reported that they have positive attitude towards HDP training, because HDP training is an instrument to improve instructional skills of the teachers. According to Anderson (2004) as indicated in Addis Tsegeye (2008), the educational effectiveness depends on the attitudes of the teachers.

One of the HDP Candidate and participant of this study in the interview session says: "My perception towards HDP is positive because the program is a big tool for teachers to develop professional knowledge on how to teach the learners. After I participated in HDP training, even my students performed better than before. In HDP training program, we share experience with each other. In our group, for instance, there are experienced teachers and we share their experience during group discussion session and this experience has a great role in the classroom instruction".

Another HDP candidate in the interview has further explained how HDP training changed his previous perception towards HDP training and summarized this theme: "Before being I engaged in HDP training, I am not that much more interested towards the training. Since I am education graduate, I always ask myself what is new from this training. After I participated in HDP training, I developed positive attitude towards the HDP training because from this training, I acquired necessary practical professional knowledge like different methods of teaching, assessment methods, implementation of active learning methods in the large class size etc.".

A successful innovation depends substantially on teachers' attitude towards proposed curriculum alternatives. Students with teachers of positive attitude towards teaching and the curriculum are found to be highlevel achievers in learning Keynes(1986), Cooper (1986), Chalhan (1988) consider the teachers' attitude as a very important aspect in the teaching process and suggested that teachers' attitude towards the subject taught is one of the commonly study is Sharing, Discussing, and Practicing. HDP requires candidates effort and they have to practice again and again to improve their teaching methodology and assessment techniques" (Another participant). The program has been assumed to provide teacher educators with a practical program to support their development as effective teachers and reflective practitioners with enhanced professional status (MOE, 2003). The HDP is skill-oriented training which each candidate tries to rest the lessons of each session in the classroom and reflects on his/her practice. The focus is on the learning process and relates directly to teaching methodology and practice (Addis Tsegeye,2008).

On the other hand, the HDLs and Tutors in group discussion explained that the opposite of learning is forgetting. Teaching is a profession. Hence, a profession always needs training. HDLs and HDTs felt that though HDP module content and undergraduate pedagogical course contents are different, the teacher needs to update his/her knowledge. As stated in OECD (2009), no matter how good pre-service training for teachers is, it cannot 
be expected to prepare teachers for all the challenges they will face throughout their careers.

Education systems therefore seek to provide teachers with opportunities for in-service professional development in order to maintain a high standard of teaching and to retain a high quality teacher workforce. Furthermore, teaching is a complex task. Even experienced teachers confront great challenges each year, including changes in subject content, new instructional methods, advances in technology, changed laws and procedures, and student learning needs. Educators who do not experience effective professional development do not improve their skills, and student learning suffers (Mizell,2010).

The majority of HDLs and HDTs in the interview said that candidates are not interested in the some content of HDP module. They felt that most of the time, the candidates disregard the examples and cases written in the module by raising the value of cases/examples which are written in the HDP module for their professional development.

Other participant of this study explained how the HDP Candidates disregard examples and case studies by substantiating the above idea with an example. In social inclusion part, for instance says: Tamiru is in Grade 7 . $\mathrm{He}$ is good at Mathematics, but he can hardly read the simplest material. They say what is the importance of this example for my professional development? Due to this problem, we jump the case studies and examples part and proceed to the next part. On the other hand, HDLs and HDTs felt that some parts of the contents description are shallow. They reported that descriptions are not supported by empirical studies. Due to this problem, teachers/candidates are reluctant to do the activities in the session. They get bored in the HDP session. And they say what new information that we learn from this material? On the other hand, before starting the HDP session, candidates say the module needs revision even after looking at the date written on the HDP module (2011).

\section{Instructor's Perceptions on HDP Training}

HDP Graduates in the study areas (112) were asked to express their opinions using likert scales on various issues. The result is indicated in table 1 as follows:

Table 2: HDP graduate instructors' perceptions towards HDP training

\begin{tabular}{|c|c|c|c|}
\hline No. & Items & $\mathbf{M}$ & SD \\
\hline 1 & HDP training has helped me to improve my active learning skills. & 2.8 & 1.2 \\
\hline 2 & HDP training has improved my relationship with students. & 2.9 & 1.3 \\
\hline 3 & HDP training has motivated me improve my pedagogical skills. & 3.0 & 1.4 \\
\hline 4 & The program helped me to become a role model of good practice. & 3.4 & 1.6 \\
\hline 5 & The program has helped me to improve my assessment skills. & 3.2 & 1.5 \\
\hline 6 & The program has helped me to improve my action research skills. & 3.0 & 1.4 \\
\hline 7 & HDP training has motivated me to implement new teaching methods. & 2.8 & 1.2 \\
\hline 8 & The HDP observation feedback has not helped me to improve my teaching methods. & 1.2 & 0.8 \\
\hline 9 & HDP certification was a positive motivation to complete my course. & 3.4 & 1.6 \\
\hline 10 & The HDP training has helped me to improve my relations with the community. & 3.6 & 1.7 \\
\hline
\end{tabular}

\section{$\mathbf{M}=$ Mean $\quad \mathbf{S D}=$ Standard Deviation}

As indicated in table 2, all instructors in the study areas have positive perceptions towards HDP on multiitems. This result is directly related with the ideas of the Ministry of Education stated in 2003 that basically aiming to improve the quality of education in Ethiopia is introducing a Higher Diploma Program (HDP), a licensing training Program that is aimed at developing the skills and professionalism of teacher educators. This Program was developed in 2003 to support the implementation of the Teacher Education System Overhaul (TESO). The MOE has now made it compulsory (UNESCO, 2007). That is why all instructors have reflected positive perceptions towards HDP and its various related aspects.

\section{Major Practices of Instructors in HDP Training}

The major practices of HDP graduate instructors are indicated in table 3 as follows: 
Table 3: Instructors' major practices in HDP training

\begin{tabular}{|c|c|c|c|}
\hline No. & Items & $\mathrm{M}$ & SD \\
\hline 1 & I can implement various teaching methods as necessary. & 3.0 & 1.4 \\
\hline 2 & I become a role model in every practice. & 4.0 & 1.9 \\
\hline 3 & I work hard to make myself a better reflective teacher. & 4.2 & 2.2 \\
\hline 4 & I can manage my time properly. & 5.0 & 2.4 \\
\hline 5 & I can conduct action researches independently and collaboratively. & 3.0 & 1.4 \\
\hline 6 & I can assess my students' performance through criteria. & 2.8 & 1.2 \\
\hline 7 & I actively participate in community services as necessary. & 3.2 & 1.5 \\
\hline 8 & I can plan on various academic sessions. & 2.6 & 1.3 \\
\hline 9 & I can apply different active learning methods in my actual classes. & 3.0 & 1.4 \\
\hline 10 & I can manage my classroom properly. & 4.0 & 1.9 \\
\hline
\end{tabular}

\section{$\mathbf{M}=$ Mean $\quad \mathbf{S D}=$ Standard Deviation}

The results in table 3 revealed that all instructors in higher institutions implemented HDP successfully. This is because the mean results are all greater than the expected mean (2.5). This finding is related with the fact that learning is a social experience, so professional growth is usually fostered through exchange, critique, exploration and formulation of new ideas (Dadds, 2001). Furthermore, if teachers allow themselves to become students of their own extraordinary self-education, they would be very well placed to facilitate the self-education of others (Underhill, 1992). This implies that student achievement is dependent on the efforts teachers make to move themselves through various developmental stages. In relation to this, Sadker and Sadker (2000) stated that money spent to increase teacher qualification through professional training improves students' academic performance more than money invested in other areas.

\section{Expected Challenges of Instructors in HDP Training}

The instructors (129) were asked through questionnaire to tell the expected challenges in their work areas towards their HDP training. The result is indicated in table 4 as follows.

Table 4: Instructors' challenges in HDP training

\begin{tabular}{|l|l|l|l|}
\hline No. & \multicolumn{1}{|c|}{ Items } & M & \multicolumn{1}{c|}{ SD } \\
\hline 1 & Low Motivation from the side of the HDP Candidates & 4.6 & 2.1 \\
\hline 2 & Time management techniques are difficult & 3.0 & $1 . .4$ \\
\hline 3 & The teaching methods are difficult to implement in classrooms & 4.0 & 1.9 \\
\hline 4 & Low support and follow up by stakeholder & 4.8 & 2.2 \\
\hline 5 & Teaching workload & 4.4 & 2.1 \\
\hline 6 & Lack of resources to implement HDP in classrooms & 4.0 & 1.9 \\
\hline 7 & Higher Diploma Leaders Lacks Experience & 2.6 & 1.3 \\
\hline 8 & Low Incentive & 5.0 & 2.4 \\
\hline 9 & Absenteeism & 3.8 & 1.7 \\
\hline 10 & Low value for HDP certificate & 3.4 & 1.6 \\
\hline
\end{tabular}

$\mathbf{M}=$ Mean $\quad \mathbf{S D}=$ Standard Deviation

The majority participants were discussed in challenges of smooth running of the HDP training. Ten major challenges were discussed: Low incentive, follow up and support from the side of the university, low motivation, Low motivation from the side of HDP candidates, Low regard from the various Departments, the lack of experience, lack of resources, the difficulty of teaching methods, time management and Low value for HDP Certificate.

Many participants in this study felt that the university and colleges provide low incentive for HDP Leaders, coordinators, and HDP candidates. They reported that the incentive mechanism of all institutions is very low. This is true that incentives budgeted for HDP Candidates, HDP Leaders, and Coordinators is not that much more encouraging. In addition, spending more may allow for greater intensity: higher quality, more time for learning, and more follow-up support as educators apply their learning (Mizell, 2010). Professional learning is the most important investment school districts can make to help retain teachers, improve instructional skills, foster professional growth, and advance student achievement. While PD is often required and well-funded, there is evidence that teachers often find little worth in the offerings available to them. Therefore, the most useful PD should be strategically structured for value to the teacher and efficiency in the classroom with the ultimate goal of positively impacting student growth.

\section{SUMMARY, CONCLUSION AND RECOMMENDATIONS}

This study assessed the instructors' perceptions, practices and challenges towards HDP in higher institutions. In 
order to achieve such objective, the following research questions were formulated:

1. What perceptions do instructors hold in implementing HDP?

2. What are the major practices employed by instructors after completing HDP?

3. What challenges do instructors' face in implementing HDP?

The data of the study was gathered through observation, interview and questionnaire. In the study the following findings were obtained:

$>$ Most instructors (about 80\%) were not implementing various active learning methods while teaching lessons.

$>$ All instructors in DMU University and its clusters had positive perceptions towards the importance of HDP.

$>$ Low incentives, absenteeism and lack of support and encouragement were the major challenges in order to implement HDP successfully.

\section{Conclusion}

HDP training contributes a lot for quality education because it improves professional knowledge of the teacher and this in turn improves students' academic performance. However, HDP training module still needs revision, because some contents of HDP modules are below standard. That means some of contents of HDP module are written in the primary and secondary school context than higher education context. Although the program is important for teachers to improve their professional knowledge, the program currently facing a number of challenges that affect the smooth running of the HDP training. The challenges emanated mainly from four directions/sides such as university, departments, HDP candidates, HDLs and Coordinators. From the side of university, there is low incentive, lack of follow up and support and these challenges may impede the success of the program. On the other hand, HDLs, HDP Candidates as well as Coordinators have low motivation towards the program because of lack of follow up and support and low incentive from the side of university. The university follow up and support is not encouraging. Besides, there is low regard from the side of the department because the departments assign the teachers in various routine activities in the HDP session days. Finally, the value for HDP Certificate is unclear because there is low value for HDP Certificate.

\section{Recommendations}

Teachers in Debre Markos University and its cluster colleges should improve their skills, knowledge and attitudes while taking HDP trainings. Having this in mind, the study recommends the following strategies as a remedy for the prevailing problem:

1. The university should better to discuss and revise the HDP module with concerned bodies.

2. HDP office should give equal emphasis to the follow-up service like that of initial training. There should be on workplace support that pressurized instructors to use the training skills.

3. The University should follow and motivate the candidate's by using different incentive mechanisms in order to attract other staff members towards the program.

4. MOE needs to revisit the curriculum manual in collaboration with that of University professionals.

Therefore, future researchers and scholars can conduct further study on HDP training and its impact on students' academic performance to better understand the positive impact of this training program on quality education in general and students' academic performance in particular. Teaching quality and school leadership are the most important factors in raising student achievement. Educators learn to help students learn at the highest levels. Many people may not be aware of their local school system's methods for improving teaching and student learning.

\section{Acknowledgement}

We would like to thank DMU for its financial support that helped us to complete the study. Our thanks also go to instructors who actively participated in giving the necessary information in DMU and its cluster colleges.

\section{References}

Adula Bekele. (2008). Application of Higher Diploma Program Training Skills in Classroom Instruction: The Case of Education Faculty, Jimma University, Ethiopia.

Ashenafi Tesfaye. (2017). Exploring the Implementation and Opportunities of HDP Program for Classroom Instruction, the Case of Dire Dawa University.

Bekalu Atnafu. (2006). Reflections on Higher Diploma Program (HDP): The Case of St. Mary's University College.

Blackmon. (2013), Teachers' Perceptions of Professional Development Activities Which Result In Successful Integration of Classroom Instructional Technologies, Georgia Southern University.

Creswell, J.W. (2012). Educational Research: Planning, Conducting, and Evaluating Quantitative and Qualitative 
Research 4th edition, University of Nebraska-Lincoln.

Desalegn Chalchisa. (n.d.). Continuous Teacher Professional Development: The Ethiopian Context: Addis Ababa University, Ethiopia.

Guskey, T.R. (2002). Professional Development and Teacher Change, Teachers and Teaching: Theory and Practice, Vol. 8, No. 34.

MOE. (2011). Higher Diploma Program for Teacher Educators. Addis Ababa.

MOE. (2009b). Continuous Professional Development for Primary and Secondary School Teachers, Leaders and Supervisors in Ethiopia: The Framework. Ministry of Education, Ethiopia.

Obanya, P. (2007). Major Determinants of Higher Education Pedagogy.UNESCO Newsletter, Vol. 9, No.1.

Yilfashewa Seyoum. (2011). Invigorating Quality through Professional Development Programs in Ethiopian Higher Education Institutions: Implications for Curriculum Enactment atHaramaya University, International Journal of Social Sciences and Education ISSN: 2223-4934, Volume 1.

Zelalem Zekarias. (2017). Teachers' Perception of Higher Diploma Program as Opportunity for Promoting Professional Development in Arba Minch University (Ethiopia): A Qualitative Inquiry. 